\title{
Adefovir dipivoxil, tenofovir disoproxil fumarate or lamivudine; which is suitable monotherapy medication in the patients with chronic hepatitis B virus infection? one year experience
}

\begin{abstract}
Introduction: The hepatitis B virus infection is responsible for more than one million deaths all over the world. This study design is to compare the efficacy of Lamivudine (LAM), Adefovir Dipivoxil (ADV) or Tenofovir Disoproxil Fumarate (TDF) monotherapy in chronically infected hepatitis B patients.

Methods: We design a prospective cohort study and select patients who were under treatment with TDF $(300 \mathrm{mg} /$ day), ADV $(10 \mathrm{mg} /$ day) and LAM $(100 \mathrm{mg} /$ day $)$. After matching patient's primary data and on base of our inclusion and exclusion criteria; 19, 20 and 19 patients were enrolled in TDF, LAM and ADV groups, respectively. Then, we evaluated patients at 6 and 12 month after treatment.

Results: Patents primary data was closely matched. After 6 month medication, ALT level in 7 patients (36.8\%), 12 patients $(60 \%)$ and 6 patients $(31.6 \%)$ of TDF, LAM and ADV groups were back to normal range, respectively $(\mathrm{P}>0.05)$. All drugs significantly decrease ALT level after 6 month therapy $(\mathrm{P}<0.0001)$. After 12 month, ALT level in 3 patients $(37.5 \%), 14$ patients $(73.7 \%)$ and 6 patients $(35.3 \%)$ of TDF, LAM and ADV group were comebacks to normal rang, respectively. LAM significantly had better effect on ALT level $(\mathrm{P}<0.05)$. After 12 month therapy, seroconversion was observed in $40 \%$ of ADV group patients ( 2 of $5 \mathrm{HBeAg}$ positive) and $33.3 \%$ of TDF group patients ( 2 of $6 \mathrm{HBeAg}$ positive) $(\mathrm{P}>0.05)$. Finally, response to treatment was observed in 5 patients $(45.5 \%), 7$ patients $(35 \%)$ and 2 patients $(10.5 \%)$ of TDF, LAM and ADV group, respectively $(\mathrm{P}>0.05)$.
\end{abstract}

Conclusion: LAM had significantly more potential to normalized ALT level. But, there were no significant differences between TDF, ADV and LAM to reduce the load of virus DNA and seroconversion of $\mathrm{HBeAg}$.

Keywords: adefovir dipivoxil, chronic hepatitis b, tenofovir disoproxil fumarate, lamivudine
Volume I Issue 3 - 2014

\author{
Farhang Babamahmoodi,' Parisa Arashnia,' \\ Mohsen Asouri, ${ }^{2}$ Ali Asghar Ahmadi, ${ }^{3}$ \\ Mohammadreza Haghshenas,' Abdolreza \\ Babamahmoodi $^{4}$ \\ 'Anti-microbial Drug Resistance Research Center, Mazandaran \\ University of Medical Sciences, Iran \\ ${ }^{2}$ North research center-Pasteur institute of Iran, Iran \\ ${ }^{3}$ Shahrivar hospital, Mazadaran University of medical sciences, \\ Iran \\ ${ }^{4}$ Health management research center, Baqiyatallah University of \\ medical sciences, Iran
}

\section{Correspondence: Parisa Arashnia, Anti-microbial Drug Resistance Research Center, Mazandaran University of Medical Sciences, Sari, Iran, Tel 09। I I230702,} Email Farhang.baba@yahoo.com

Received: June 0I, 2014 | Published: June 18, 20I4
Abbreviations: LAM, lamivudine; ADV, adefovir dipivoxil; TDF, tenofovir disoproxil fumarate; PT, prothrombin time; ALT, alanine transaminase; $\mathrm{HBeAg}, \mathrm{HBe}$ antigen.

\section{Introduction}

Hepatitis B virus(HBV) is a member of the genus Orthohepadnavirus of Hepadnaviridae family. ${ }^{1}$ Hepatitis B is one of the most important liver infectious inflammatory disorders which is induced by the HBV and causes inflammation in the hepatic tissues, vomiting, jaundice, etc. ${ }^{2}$ According to statistical reports, $5 \%$ of world's population is suffered from chronic (long-term) HBV infection in the worldwide. ${ }^{3}$ Chronic HBV infection is usually associated with hepatocellular carcinoma as well as hepatic cirrhosis which can lead to death. ${ }^{4}$ It has been reported that chronic HBV infection is associated with chronic hepatic inflammation (which is called chronic hepatitis) and leads to liver cirrhosis during several years after infection. ${ }^{5}$ Also, chronic HBV infection increased the rate of incidence of hepatocellular carcinoma in patients. ${ }^{6}$

According to the statistics, hepatitis $\mathrm{B}$ and $\mathrm{C}$ induces $50 \%$ of hepatocellular carcinomas in European countries. ${ }^{7}$ Therefore, patients with chronic HBV infection should deprive themselves from consumption of alcohol inasmuch as it increases the risk of hepatic cirrhosis and hepatocellular carcinomas. ${ }^{8}$

As for the prevalence and complication of this disease, find a well medication is very important. Nevertheless, type of management and indication of antiviral therapy is difference and depended to patients' condition. ${ }^{9}$ Seven drugs approve for treatment of chronic HBV infection that included; interferon alfa, ${ }^{10,11}$ peginterferon alfa2a ${ }^{12}$ Lamivudine (LAM) ${ }^{13}$ Adefovir Dipivoxil (ADV), ${ }^{14}$ entecavir, ${ }^{15}$ Telbivudine ${ }^{16}$ and Tenofovir Disoproxil Fumarate (TDF). ${ }^{17}$

Lamivudine is a second-generation nucleoside analogue. This drug inhibits HBV replication and improves liver histology. However, viral gene mutation that laid to Lamivudine resistance is event frequently. ${ }^{18}$ Recently, Adefovir Dipivoxil, a prodrug of Adefovir, was approved for used in chronic hepatitis B patients. ${ }^{14,19,20}$ Also, TDF is another most common drug for treatment of chronic hepatitis B virus infection. ${ }^{21}$ Our cohort study examined comparison of the efficacy of ADV, TDF and LAM in the patients who suffered from chronic hepatitis B virus infection. 


\section{Patients and methods}

\section{Patient's selection}

We design a prospective cohort study and select patients who were under treatment with ADV, TDF or LAM. For this aim, we collected patient's demographic and past lab test data (before medication) and select patients who had same condition. Our inclusion criteria included all patients with chronic HBV disease who had over 20000 $\mathrm{IU} / \mathrm{ml} \mathrm{HBV}$ DNA and ALT higher than 2 fold of normal range in lab test or had liver positive histological evidence of HBV disease and taking antiviral medication (ADV, TDF or LAM) from a maximum of 4 months ago. Our exclusion criteria included all patients who were under treatment with Interferon, HBC, HBD or HIV infection, decompensated liver disease (serum bill $>2 / 5, \mathrm{PT}>3 \mathrm{~s}$, history of ascites, abnormal Albumin, hepatic Encephalopathy), other liver disease (autoimmune hepatitis, drug-induced hepatitis), history of any transplantation, liver mass and patients who recently treated with corticosteroid.

\section{Study design and data collection}

Before entering patients into the study, their all data including; gender, age, history of disease, history of smoking, prothrombine time (PT), serum creatinine levels, alanine transaminase (ALT), HBe antigen (HBeAg), HBV DNA load were collected. On base of inclusion and exclusion criteria and after matching patients demographic and first lab test (before treatment) data, we selected 19, 20 and 19 patients for ADV, LAM and TDF groups, respectively. Then we follow patients for one year, from their medications were started. Patients in ADV, LAM and TDF groups were under treatment with $10 \mathrm{mg} /$ day Adefovir Dipivoxil, $100 \mathrm{mg}$ /day Lamivudine and $300 \mathrm{mg} /$ day Tenofovir Disoproxil Fumarate, respectively. After entering patients into the study, their lab test data including; alanine transaminase (ALT), HBe antigen (HBeAg) and HBV DNA level were collected at 6 and 12 months of their treatment.

\section{Statistical analysis}

Statistical data analysis was performed by SPSS version 16 . Categorical data were analyzed by two-sided Fisher exact test and chi-square test and Quantitative data were analyzed using student $t$ test. $\mathrm{P}$ value under 0.05 considers as a significant level.

\section{Results}

Patients mean age in ADV, LAM and TDF groups were $34.73 \pm 11.42$, $39.85 \pm 12.33$ and $34.63 \pm 11.72$ years, respectively $(\mathrm{P}>0.05) .10$ patients $(52.6 \%)$ in ADV, 15 patients $(75 \%)$ in LAM and 15 patients (78.9\%) in TDF groups were male ( $\mathrm{P}>0.05)$. No significant difference was observed between groups in history of disease, smoking and first lab test included; PT time, serum creatinine level, ALT level, HBV DNA copy and $\mathrm{HBeAg}$ positivity $(\mathrm{P}>0.05)$ (Table 1$)$.

Table I Demographic and baseline characteristics of the patients

\begin{tabular}{llll}
\hline & ADV Group & LAM Group & TDF Group \\
\hline Age & $34.73 \pm 11.42$ & $39.85 \pm 12.33$ & $34.63 \pm 11.72$ \\
Gender (male) & $10(52.6 \%)$ & $15(75 \%)$ & $15(78.9 \%)$ \\
history of disease & $1(5.3 \%)$ & $3(15 \%)$ & $1(5.3 \%)$ \\
Smoking & $4(21.1 \%)$ & $4(20 \%)$ & $1(5.3 \%)$ \\
PT time (s) & $12.66 \pm 0.5 \mathrm{I}$ & $12.63 \pm 0.46$ & $12.68 \pm 0.6 \mathrm{I}$ \\
Cr level (mg/dl) & $0.82 \pm 0.11$ & $0.86 \pm 0.12$ & $0.83 \pm 0.14$ \\
ALT level & $167.31 \pm 58.23$ & $149.35 \pm 48.18$ & $134.52 \pm 34.51$ \\
HBeAg (Positive) & $5(26.3 \%)$ & $3(15 \%)$ & $6(31.6 \%)$ \\
HBV DNA level & $53683470 \pm 27263501$ & $71755908 \pm 27059394$ & $63624869 \pm 29142710$ \\
\hline
\end{tabular}

\section{Biochemical response}

The mean of ALT before treatment in ADV, LAM and TDF groups were $147.31 \pm 58.23 \mathrm{U} / \mathrm{L}, 149.35 \pm 48.18 \mathrm{U} / \mathrm{L}$ and $134.52 \pm 34.51 \mathrm{U} / \mathrm{L}$, respectively $(\mathrm{P}>0.05)$. After 6 month medication, mean of ALT level in ADV, LAM and TDF groups were $56.94 \pm 35.72 \mathrm{U} / \mathrm{L}, 38.45$ $\pm 19.07 \mathrm{U} / \mathrm{L}$ and $49.42 \pm 22.07 \mathrm{U} / \mathrm{L}$, respectively. There was only a weakly significant difference was observed between ADV and LAM groups $(\mathrm{P}=0.049)$. Furthermore, after 6 month antiviral therapy, ALT level in 6 patients $(31.6 \%)$ of ADV, in 12 patients $(60 \%)$ of LAM and in 7 patients $(36.8 \%)$ of TDF group were back to normal range $(\mathrm{ALT}<40 \mathrm{U} / \mathrm{L})$. There was no significant difference was observer between groups $(\mathrm{P}>0.05)$. On the other hand, All three drugs significantly decreased ALT level after 6 month therapy $(\mathrm{P}<0.0001)$.

Due to TDF shortage and unavailability of sufficient quantities of it, 8 patients in TDF group changed to ADV and we categorized these

patients in group C. These patients characteristics included; the mean age was $32.75 \pm 11.37$ years, 7 cases were male, mean ALT level was $44.37 \pm 25.75 \mathrm{U} / \mathrm{L}, 3$ patients were $\mathrm{HBeAg}$ positive and mean DNA copy was $885458 \pm 213615$ (Median=72168).

After 12 month medication, mean ALT level in ADV group was $47.58 \pm 23.96 \mathrm{U} / \mathrm{L}$, in LAM group was $43.78 \pm 42.93 \mathrm{U} / \mathrm{L}$, in TDF group was $43.78 \pm 42.93 \mathrm{U} / \mathrm{L}$ and in group $\mathrm{C}$ was $38.12 \pm 16.29 \mathrm{U} / \mathrm{L}$. there was no significant difference between groups $(\mathrm{P}>0.05)$ (Table 2). Also, no significant difference in ALT level were observed between 6 month and 12 month in each groups ( $\mathrm{P}>0.05)$. But, ALT level in 6 patients $(35.3 \%)$ of ADV group, 14 patients $(73.7 \%)$ of LAM group, in 3 patients $(37.5 \%)$ of TDF group and 4 patients in group C $(50 \%)$ were back to normal range. This results show Lamivudine can be more effective than Adefovir Dipivoxil ( $\mathrm{P}=0.042)$ and Tenofovir Disoproxil Fumarate $(\mathrm{P}=0.028)$ to normalized serum ALT level after 12 month antiviral therapy. 
Table 2 Virologic and biochemical statement after 6 month and I 2 month

\begin{tabular}{llll}
\hline & ADV Group & LAM Group & TDF Group \\
\hline ALT level at 6 month & $56.94 \pm 35.72$ & $38.45 \pm 19.07$ & $49.42 \pm 22.07$ \\
ALT level at I 2 month & $47.58 \pm 23.96$ & $43.78 \pm 42.93$ & $43.62 \pm 12.09$ \\
HBeAg at 6 month & $4(21.1 \%)$ & $3(15 \%)$ & $4(21.1 \%)$ \\
HBeAg at I2 month & $3(17.6 \%)$ & $3(15 \%)$ & $1(12.5 \%)$ \\
HBV DNA level at 6 month & $95538688 \pm 64670764$ & $94026070 \pm 62192807$ & $451570 \pm 320490$ \\
HBV DNA level at I2 month & $31089155 \pm 25085083$ & $627242692 \pm 559864449$ & $4235 \pm 3624$ \\
\hline
\end{tabular}

\section{Virologic and serologic response}

Before medication, mean of HBV DNA copy in ADV, LAM and TDF groups were $53683470 \pm 2726350 \mathrm{IU} / \mathrm{ml}$, $71755908 \pm 27059394 \mathrm{IU} / \mathrm{ml}$ and $63624869 \pm 29142710 \mathrm{IU} / \mathrm{ml}$, respectively. There was no significant difference between 3 groups $(\mathrm{P}>0.05)$. After 6 month antiviral therapy, mean of HBV DNA was change to $95538688 \pm 64670764 \mathrm{IU} / \mathrm{ml}, 94026070 \pm 6219807 \mathrm{IU} / \mathrm{ml}$ and $451570 \pm 320490 \mathrm{IU} / \mathrm{ml}$ in ADV, LAM and TDF groups, respectively. At this stage, there were no significant differences exist between groups ( $\mathrm{P}>0.05)$. Also, after 12 month medication, mean of HBV DNA copy were $31089155 \pm 25085083 \mathrm{IU} / \mathrm{ml}, 627242692 \pm 559864449 \mathrm{IU} /$ $\mathrm{ml}, 4235 \pm 3624 \mathrm{IU} / \mathrm{ml}$ and $22337823 \pm 43157341 \mathrm{IU} / \mathrm{ml}$ in ADV, LAM, TDF and $C$ groups (Table 2). In the end of study, one patient in ADV group, one patient in LAM group and 3 patients in TDF group had undetectable level of HBV DNA. There was no significant difference were observed between groups $(\mathrm{P}<0.05)$. Also, in the within each groups was no statistical significant difference Between HBV DNA level before and after treatment $(\mathrm{P}>0.05)$ except TDF group. in this group, HBV DNA level after 6 month therapy was significantly lower than that's primary level $(\mathrm{P}=0.044)$.

At the beginning of treatment, 5 patients $(26.3 \%)$ in ADV group, 3 patients $(15 \%)$ in LAM group and 6 patients $(31.6 \%)$ in TDF group had $\mathrm{HBeAg}$ positive test $(\mathrm{P}>0.05)$ (Table 2$)$. HBeAg in two patients ADV and two patients of TDF group were negative after 12 month medication. There was no significant difference was observed between groups and within each group before and after treatment $(\mathrm{P}>0.05)$.

\section{Responses after 12 month treatment}

Response to Treatment defined by protocol (HBV DNA level $<1000$ $\mathrm{IU} / \mathrm{ml}$ and alanine aminotransferase level less than 1.25 times the upper limit of normal). ${ }^{16}$ According to this defined, 2 patient in the Adefovir Dipivoxil group (10.5\%), 7 patients in the Lamivudine group (35\%), 5 patient in the TDF group (45.5\%) and 2 patients in group $\mathrm{C}(25 \%)$ had response to treatment. There was no significant difference between groups $(\mathrm{P}>0.05)$.

\section{Discussion}

It has been estimated that approximately 350 to 400 million people are chronically infected with hepatitis B in the worldwide. ${ }^{3}$ Approximately, one third of these people does not control their disease permanently and therefore require treatment to reduce the risk of developing of cirrhosis, fibrosis and hepatocellular carcinoma. ${ }^{22-24}$ The main goal of treatment for chronic hepatitis B is to achieve sustained suppression of HBV transcription and reduced liver disease to prevent progression of long-term complications of this disease. ${ }^{25}$ In patients, drug selection is based on the patient's condition, medication effectiveness, and availability of a specific drug or drug resistance to anti-viral medications as well as cost of drugs. ${ }^{26}$ On the other hand, the response to anti-viral therapy for different drugs are not equal and various factors involved in the outcome of drug therapy such as age, sex, duration of treatment, viral genotype, $\mathrm{HBeAg}$ positivity, baseline HBV DNA and baseline ALT. ${ }^{27}$ The purpose of this study is evaluation of patient's response to anti-viral drugs therapy (ADV, LAM and TDF) and determines the efficacy of these procedures for finding of suitable therapeutic method.

The gender and mean age of all patients in this study was same to other studies. ${ }^{15,25,26}$ Same our study, Pradeep et al., ${ }^{20}$ in their study expressed that 6 month medication by Adefovir Dipivoxil and Lamivudine can significantly decrease ALT level and viral load in HBV patients. In their study, no significant difference was observed between Adefovir Dipivoxil and Lamivudine groups to ALT level and $\mathrm{HBeAg}$ seroconversion after 6 month therapy, ${ }^{18}$ but we have a significant decrease ALT level in Lamivudine group after 6 month. Furthermore, in this study after 12 month, Lamivudine significantly better than Adefovir Dipivoxil and Tenofovir Disoproxil Fumarate was able to normalized ALT level. In the other studies shown that ALT normalization by Lamivudine is variable between 41 to $81.8 \%{ }^{10,11,27}$

We have only one patient in ADV (5.2\%), one patient in LAM group (5\%) and 3 patients in TDF group (15.7\%) that had undetectable HBV DNA level. In the Pradeep et al. ${ }^{20}$ study, undetectable HBV DNA level was observed in 4 patients of ADV group (26.7\%) and 2 patients in LAM group (13.3\%). Also, in consistent with present study Peters MG et al., ${ }^{28}$ showed the same undetected level of virus in patients whom received TDF.

Our study revealed that the frequency of loss of $\mathrm{HBeAg}$ (seroconversion) for TDF, ADV and LAM was $19.1 \%, 8.7 \%$ and zero, respectively. These results showed that TDF has been associated with higher rates of $\mathrm{HBeAg}$ diminishing; however there is not a statistical significant difference between the drugs. Likewise with our research, Marcellin et al., ${ }^{17}$ study showed that $\mathrm{HBeAg}$ negative amount was $21 \%$ for $\mathrm{ADV}$ and was $18 \%$ for TDF which demonstrated that efficacy of TDF is in accordance to our study. We have not any seroconverted patients in Lamivudine group. Against with our study, other study reported seroconversion by Lamivudine medications between 16 to 22 percent. ${ }^{13,15,29}$ In other studies by Nelson M et al., ${ }^{30}$ Schmutz G et al., ${ }^{31}$ Stephan $\mathrm{C}$ et al., ${ }^{32}$ Jain MK et al., ${ }^{33}$ and Benhamou Y et al., ${ }^{34}$ have examined the effect of TDF in patients who suffered from both HIV and HBV simultaneously and showed that the frequency of loss of $\mathrm{HBeAg}$ effects of TDF can vary between 6 to 40 percent.

\section{Conclusion}

Our study results show Lamivudine was superior than Adefovir Dipivoxil and Tenofovir Disoproxil Fumarate to normalization hepatic function. But in other hand, Tenofovir Disoproxil Fumarate better 
than others are able to reduce viral load and HBeAg seroconversion, but not significantly. However, it seems to reach a more definitive results of clinical trials with larger sample sizes are needed.

\section{Acknowledgments}

None.

\section{Conflicts of interest}

Authors declare that there is no conflict of interest.

\section{References}

1. Schaefer S. Hepatitis B virus taxonomy and hepatitis B virus genotypes. World J Gastroentrol. 2013;13(1):14-21.

2. $\mathrm{Hu} \mathrm{KQ}$. Hepatitis B virus (HBV) infection in Asian and Pacific Islander Americans (APIAs): how can we do better for this special population? Am J Gastroenterol. 2008;103(7):1824-1833.

3. Pungpapong S, Kim W. In the eye of the B $\square$ holder: natural history of chronic hepatitis B. Hepatology. 2013;58(1):6-8.

4. Nabavi SF, Daglia M, Moghaddam AH, et al. Curcumin and Liver Disease: from Chemistry to Medicine. Compr Rev Food Sci Food Saf. 2014;13(1):62-77.

5. Protzer U, Maini MK, Knolle PA. Living in the liver: hepatic infections. Nat Rev Immunol. 2012;12(3):201-213.

6. Fallot G, Neuveut C, Buendia MA. Diverse roles of hepatitis B virus in liver cancer. Curr Opin Virol. 2012;2(4):467-473.

7. El-Serag HB. Epidemiology of viral hepatitis and hepatocellular carcinoma. Gastroenterology. 2012;142(6):1264-1273.

8. Donato F, Tagger A, Gelatti U, et al. Alcohol and hepatocellular carcinoma: the effect of lifetime intake and hepatitis virus infections in men and women. Am J Epidemiol. 2002;155(4):323-331.

9. Lai CL, Yuen MF. The natural history and treatment of chronic hepatitis B: A critical Evaluation of Standard treatment criteria and end point. Ann Intern Med. 2007;147(1):58-61.

10. Perrillo RP, Schiff ER, Davis GL, et al. A randomized, controlled trial of interferon alfa-2b alone and after prednisone withdrawal for the treatment of chronic hepatitis B. The Hepatitis Interventional Therapy Group. N Engl J Med. 1990;323(5):295-301.

11. Hoofnagle JH, Peters M, Mullen KD, et al. Randomized, controlled tria of recombinant human alfa-interferon in patients with chronic hepatitis B. Gastroenterology. 1988;95(5):1318-1325.

12. Lau GK, Piratvisuth T, Luo KX, et al. Peginterferon Alfa-2a, lamivudine, and the combination for HBeAg-positive chronic hepatitis B. $N$ Engl J Med. 2005;352(26):2682-2695.

13. Dienstag JL, Schiff ER, Wright TL, et al. Lamivudine as initial treatment for chronic hepatitis B in the United States. $N$ Engl J Med. 1999;341(17):1256-1263.

14. Marcellin P, Chang TT, Lim SG, et al. Adefovir dipivoxil for the treatment of hepatitis B e antigen-positive chronic hepatitis B. $N$ Engl J Med. 2003;348(9):808-816.

15. Chang TT, Gish RG, de Man R, et al. A comparison of entecavir and lamivudine for $\mathrm{HBeAg}$-positive chronic hepatitis B. $N$ Engl $\mathrm{J}$ Med. 2006;354(10):1001-1010.

16. Lai CL, Gane E, Liaw YF, et al. Telbivudine versus lamivudine in patients with chronic hepatitis B. N Engl J Med. 2007;357(25):2576-2588.
17. Marcellin P, Heathcote EJ, Buti M, et al. Tenofovir disoproxil fumarate versus adefovir dipivoxil for chronic hepatitis B. $N$ Engl J Med. 2008;359(23):2442-2455.

18. Marcellin P. Advances in therapy for chronic hepatitis B. Semin Liver Dis. 2002;22(Suppl 1):33-36.

19. Hadziyannis SJ, Tassopoulos NC, Heathcote EJ, et al. Adefovir dipivoxil for the treatment of hepatitis B e antigen-negative chronic hepatitis B. $N$ Engl J Med. 2003;348(9):800-807.

20. Pradeep KS, Medhi S, Asim M, et al. Evaluation of adefovir \& lamivudine in chronic hepatitis B: correlation with HBV viral kinetic, hepatic-necro inflammation \& fibrosis. Indian J Med Res. 2011;133:50-56.

21. Woo G, Tomlinson G, Nishikawa Y, et al. Tenofovir and entecavir are the most effective antiviral agents for chronic hepatitis B: a systematic review and Bayesian meta-analyses. Gastroenterology. 2010;139(4):1218-1229.

22. Liaw YF, Leung N, Kao JH, et al. Asian-Pacific consensus statement on the management of chronic hepatitis B: a 2005 update. Liver Int. $2005 ; 25(3): 472-489$

23. Lok AS, McMahon BJ. Chronic hepatitis B: update 2009. Hepatology. 2009;50(3):661-662.

24. Tong MJ, Pan CQ, Hann HW, et al. The management of chronic hepatitis B in Asian Americans. Dig Dis Sci. 2011;56(11):3143-3162.

25. European Association for the Study of the Liver. EASL Clinical Practice Guidelines: management of chronic hepatitis B virus infection. $J$ Hepatol. 2012;57(1):167-185.

26. Keeffe EB, Dieterich DT, Han SH, et al. A treatment algorithm for the management of chronic hepatitis B virus infection in the United States: 2008 update. Clin Gastroenterol Hepatol. 2008;6(12):1315-1341.

27. Chan HL, Wong VW, Tse CH, et al. Early virological suppression is associated with good maintained response to adefovir dipivoxil in lamivudine resistant chronic hepatitis B. Aliment Pharmacol Ther. 2007;25(8):891-898

28. Peters MG, Andersen J, Lynch P, et al. Randomized controlled study of tenofovir and adefovir in chronic hepatitis B virus and HIV infection: ACTG A5127. Hepatology. 2006;44(5):1110-1116.

29. Lai CL, Chien RN, Leung NW, et al. A one-year trial of lamivudine for chronic hepatitis B. Asia Hepatitis Lamivudine Study Group. $N$ Engl J Med. 1998;339(2):61-68.

30. Nelson M, Portsmouth S, Stebbing J, et al. An open-label study of tenofovir in HIV-1 and hepatitis B virus co-infected individuals. AIDS. 2003;17(1):F7-F10.

31. Schmutz G, Nelson M, Lutz T, et al. Combination of tenofovir and lamivudine versus tenofovir after lamivudine failure for therapy of hepatitis B in HIV-coinfection. AIDS. 2006;20(15):1951-1954.

32. Stephan C, Berger A, Carlebach A, et al. Impact of tenofovir-containing antiretroviral therapy on chronic hepatitis B in a cohort co-infected with human immunodeficiency virus. $J$ Antimicrob Chemother. 2005;56(6):1087-1093

33. Jain MK, Comanor L, White C, et al. Treatment of hepatitis B with lamivudine and tenofovir in $\mathrm{HIV} / \mathrm{HBV}$-coinfected patients: factors associated with response. J Viral Hepat. 2007;14(3):176-182.

34. Benhamou Y, Fleury H, Trimoulet P, et al. Anti-hepatitis B virus efficacy of tenofovir disoproxil fumarate in HIV-infected patients. Hepatology. 2006;43(3):548-555. 